\title{
PERANCANGAN PROGRAM APLIKASI HIDROGRAF SATUAN SINTESIS (HSS) DENGAN METODE GAMA 1, NAKAYASU, DAN HSS \\ ITB 1
}

\author{
Enung \\ Staf Pengajar Jurusan Teknik Sipil Politeknik Negeri Bandung, Jl.Gegerkalong Hilir Ds.Ciwaruga Kotak Pos \\ 1234 Bandung 40012, \\ E-mail: enung@polban.ac.id, enung1982@gmail.com
}

\begin{abstract}
This paper present about design of Unit hydrographs (UH) application program using three methods of Synthetic Unit Hydrograph namely Gama 1, ITB 1, and Nakayasu. Unit hydrographs are either determined from gauged data or derived using empirically-based synthetic unit hydrograph procedures. In Indonesia, the discharge records may not be available either for several locations or for long time scales, and therefore synthetic unit hydrographs are crucial in flood and water re-sources management. Computer programs were developed to provide a means for rapid analysis. of rainfall and run off data. The purpose of this research is to design computer application program analysis based on three methods of Synthetic Unit Hydrograph namely Gama 1, ITB 1, and Nakayasu. This computer application program use Visual Basic 6.0 as the programming language. This research began from literature studies, lay out design of the display program, the developed of the algorithm, and then carried out using the programming language Visual Basic program, then perform verification and validation program using secondary data. The accomplished results show that computer application program namely Synthetic Unit Hydrograph Program can be used to analyze unit hydrograph which show in table and graph.
\end{abstract}

Key Words : Synthetic Unit Hydrographs, GAMA 1, ITB 1, Nakayasu, Visual Basic 6.0

\section{Pendahuluan}

\section{I.1.Latar Belakang}

Perencanaan penanggulangan banjir diperlukan analisis yang komprehensif dari berbagai bidang, antara lain bidang hidrologi, hidrolika, lingkungan, dan bidang lainnya yang terkait. Dalam perencanaan bangunan sumber daya air khususnya pengendalian banjir, diperlukan data debit banjir rencana. Besaran debit ini akan menentukan dimensi bangunan yang sangat erat kaitannya dengan resiko nilai ekonomis dari bangunan yang direncanakan.Untuk keperluan tersebut, telah banyak metode yang diusulkan oleh pakar hidrologi dari berbagai negara sesuai dengan macam dan jumlah data yang tersedia, seperti Metode Hidrograf Satuan Sintetis (Snyder, Nakayasu, GAMA I, GAMA II, Limantara, ITB 1, ITB II), dan lain-lain.

Selain pemilihan metode yang tepat untuk diterapkan di suatu wilayah, tingkat ketelitian analisis juga akan menentukan besaran debit banjir yang dihasilkan. Oleh karena itu diperlukan alat bantu analisis berupa perangkat lunak (software). Berbagai alat bantu analisis mulai dari yang sederhana seperti Ms.Excel sampai dengan software khusus hidrologi sudah banyak digunakan, contohnya software Hydrologic Modeling System (HMS), Hydro Cad, SOBEK, HyMOS, HAVARA T-01, dan lainnya. Dari beberapa software yang ada, sebagian besar adalah produk luar negeri yang didesain menggunakan metode yang sesuai dengan lokasi dimana software tersebut dikembangkan. Sedangkan software yang mengakomodir metode yang dikembangkan di Indonesia masih terbatas, contoh software yang sudah dikembangkan adalah HAVARA T-01 yang dikembangkan oleh Himawan (2003), tetapi software belum dipublikasikan secara luas sehingga pemakaiannya masih terbatas. 
Berdasarkan permasalahan tersebut dan dari berbagai kajian yang sudah dilakukan, maka perlu dirancang suatu perangkat lunak untuk menganalisis debit banjir dengan menggunakan metode Hidrograf Satuan Sintetik yang dikembangkan di Indonesia seperti metode HSS GAMA 1, dan HSS ITB 1. Sehingga analisis yang dilakukan dalam perencanaan sumber daya air dapat lebih mewakili kondisi yang ada di Indonesia

\section{Landasan Teori Hidrograf Satuan}

Hidrograf aliran menggambarkan suatu distribusi waktu dari aliran (dalam hal ini debit) di sungai dalam suatu DAS pada suatu lokasi tertentu. Hidrograf aliran suatu DAS merupakan bagian penting yang diperlukan dalam berbagai perencanaan bidang Sumber Daya Air. Terdapat hubungan erat antara hidrograf dengan karakteristik suatu DAS, dimana hidrograf banjir dapat menunjukkan respon DAS terhadap masukan hujan tersebut (Natakusumah dkk, 2011).

Konsep hidrograf satuan yang banyak digunakan untuk melakukan transformasi dari hujan menjadi debit aliran pertama kali dikenalkan pada tahun 1932 oleh L.K. Sherman. Hidrograf satuan didefinisikan sebagai hidrograf limpasan langsung (tanpa aliran dasar) yang tercatat di ujung hilir DAS yang ditimbulkan oleh hujan efektif sebesar satu satuan $1 \mathrm{~mm}$ yang terjadi secara merata di seluruh DAS dengan intensitas tetap dalam suatu durasi tertentu (Triatmojo, 2010). Beberapa asumsi dalam penggunaan hidrograf satuan adalah sebagai berikut:

a. Hujan efektif mempunyai intensitas konstan selama durasi hujan efektif. Untuk memenuhi anggapan ini maka hujan deras untuk analisis adalah hujan dengan durasi singkat.

b. Hujan efektif terdistribusi secara merata pada seluruh DAS. Dengan anggapan ini maka hidrograf satuan tidak berlaku untuk DAS yang sangat luas, karena sulit untuk mendapatkan hujan merata di seluruh DAS.

\section{Konsep Hidrograf Satuan Sintetis}

Karakteristik bentuk hidrograf yang merupakan dasar dari konsep hidrograf satuan ditunjukan pada Gambar 1. Prinsip penting dalam penggunaan hidrograf satuan dapat sebagai berikut.

a. Lumped response, hidrograf menggambarkan semua kombinasi dari karakteristik fisik DAS yang meliputi (bentuk, ukuran, kemiringan, sifat tanah) dan karakteristik hujan.

b. Time Invariant, hidrograf yang dihasilkan oleh hujan dengan durasi dan pola yang serupa memberikan bentuk dan waktu dasar yang serupa pula.

Linear Response, respons limpasan langsung dipermukaan (direct runoff) terhadap hujan efektif bersifat linear, sehingga dapat dilakukan superposisi hidrograf.

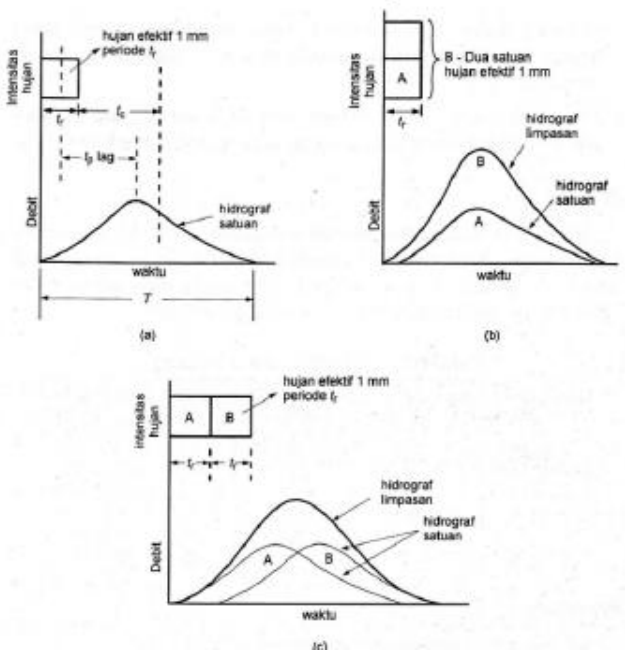

Gambar 1. Prinsip Hidrograf Satuan

\section{Hidrograf Satuan Sintetis}

Apabila data hidrologi tidak tersedia untuk menurunkan hidrograf satuan, maka dibuat Hidrograf Satuan Sintetis (HSS) yang didasarkan pada karakteristik DAS tersebut. Beberapa metode HSS antara lain metoda Snyder-SCS, Snyder-Alexeyev, Nakayasu, GAMA-1, HSS- $\alpha \beta \gamma$ dan Limantara. Selain itu Program HEC-HMS (pengembangan dari program HEC-1) juga sangat umum digunakan. Metoda Snyder-SCS, Snyder- Alexeyev, Nakayasu dikembangkan diluar negeri, sedangkan metoda perhitungan hidrograf satuan sintetis yang pertama dikembangkan di Indonesia adalah metoda HSS Gama-1 yang dikembangkan di Universitas Gajah Mada (Harto, 1993). Selanjutnya dikembangkan metode HSS $\alpha \beta \gamma$ di Institut Teknologi Sepuluh

PUEESI PERANCANGAN PROGRAM HIDROGRAF SATUAN SINTESIS 9HSS) DENGAN METODE GAMA 1, NAKAYASU, DAN HSS ITB 1 
November (Lasidi et.al, 2003) dan HSS Limantara di Universitas Brawijaya (Lily, 2008 dalam Natakusumah dkk, 2011).

\section{HSS GAMA 1}

Pemilihan metode GAMA 1 sebagai dasar untuk menghitung hidrograf satuan berdasarkan teori bahwa hidrograf satuan sintetik ini ditemukan dari 25 hasil penelitian terhadap sungai-sungai di pulau Jawa. Sri Harto (2000) menjelaskan bahwa persamaan lain yang dikembangkan di luar Indonesia perlu dicermati jika akan digunakan di Indonesia karena persamaan-persamaan tersebut dikembangkan di daerah dengan sifat hidrologi yang sangat berbeda dengan di Indonesia. Secara lengkap parameter parameter yang digunakan dalam metode HSS Gama I adalah sebagai berikut.:

1. Faktor-sumber (SF), yaitu perbandingan antara jumlah panjang sungai-sungai tingkat satu dengan jumlah panjang sungai semua tingkat.

2. Frekuensi-sumber (SN), yaitu perbandingan antara jumlah pangsa sungai-sungai tingkat satu dengan jumlah pangsa sungai semua tingkat.

3. Faktor-simetri (SIM), ditetapkan sebagai hasil kali antara factor lebar (WF) dengan luas relatif DAS sebelah hulu (RUA).

4. Faktor-lebar (WF) adalah perbandingan antara lebar DAS yang diukur dari titik di sungai yang berjarak $0,75 \mathrm{~L}$ dan lebar DAS yang diukur dari titik di sungai yang berjarak $0,25 \mathrm{~L}$ dari tempat pengukuran.

5. Luas relatif DAS sebelah hulu (RUA) adalah perbandingan antara luas DAS sebelah hulu garis yang ditarik melalui titik di sungai terdekat dengan titik berat DAS dan tegak lurus terhadap garis yang menghubungkan titik tersebut dengan tempat pengukuran, dengan luas DAS total (A).

6. Jumlah pertemuan sungai (JN) yang besarnya sama dengan jumlah pangsa sungai tingkat satu dikuGama Irangi satu.

7. Kerapatan jaringan kuras (D), yaitu panjang sungai persatuan luas DAS $(\mathrm{km} / \mathrm{km} 2)$.

HSS Gama I memiliki empat variabel pokok (Gambar 2) yaitu waktu naik (TR), debit puncak (Qp), waktu dasar (QB), dan sisi resesi yang ditentukan dari koefisien tampungan $(\mathrm{k})$.

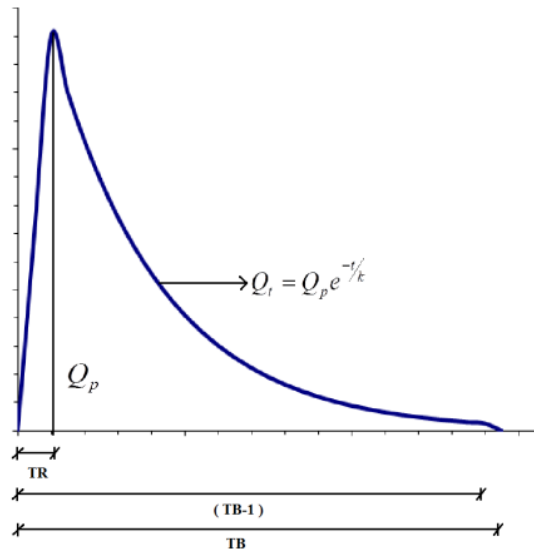

Gambar 2. Skema HSS Gama 1

\section{HSS ITB 1}

Untuk menganalisis hidrograf satuan sintetis pada suatu DAS dengan cara ITB perlu diketahui beberapa komponen penting pembentuk hidrograf satuan sintetis berikut 1) Tinggi dan Durasi Hujan Satuan. 2) Time Lag (TL), Waktu Puncak (Tp) dan Waktu Dasar (Tb), 3) Bentuk Hidrograf Satuan dan 4) Debit Puncak Hidrograf Satuan (Natakusumah,dkk,2011).

\section{Waktu Puncak (Tp) dan Waktu Dasar (Tb)}

Waktu puncak Hidrograph Satuan Sintetis ditentukan oleh harga time lag. Time lag adalah waktu tercapainya debit puncak dihitung dari pusat hujan satuan. Ada banyak rumus yang telah diajukan oleh berbagai peneliti berdasarkan hasil penelitian di berbagai DAS baik yang berada di Luar negeri maupun dalam negeri.

HSS ITB-1 menggunakan rumus time lag menurut Snyder namun dengan penyederhanaan harga $\mathrm{Lc}=0.5 \mathrm{~L}$, sehingga rumus Snyder dapat dituliskan sebagai berikut:

$$
t p=C_{t} \times 0.8122 \times L^{0,6}
$$

Jika rumus time lag menggunakan rumus Snyder dan jika Tr adalah durasi hujan satuan maka nilai waktu puncak (Tp) adalah sebagai berikut:

$$
\mathrm{Tp}=\mathrm{tp}+0.50 \mathrm{Tr}
$$


Jika time lag menggunakan rumus Nakayasu, maka nilai waktu puncak adalah sebagai berikut:

$$
\mathrm{Tp}=\mathrm{tp}+0.60 \mathrm{tp}
$$

Secara teoritis $\mathrm{Tb}$ berharga tak berhingga (seperi halnya cara Nakayasu), namun prakteknya $\mathrm{Tb}$ dapat dibatasi sampai lengkung turun mendekati nol, misal $\mathrm{Tb}=(10 \mathrm{~s} / \mathrm{d}$ 20)*Tp. Durasi hujan satuan umumnya diambil $\mathrm{Tr}=1$ jam, namun dapat dipilih durasi lainnya asalkan dinyatakan dalam satuan jam (misal 0.5 jam , 10 menit $=1 / 6$ jam $)$. Koefisien $\mathrm{Ct}$ diperlukan dalam proses kalibrasi harga Tp. Harga standar koefisien $\mathrm{Ct}$ adalah 1.0, namun jika saat proses kalibrasi dijumpai $\mathrm{Tp}$ perhitungan lebih kecil dari Tp pengamatan, harga diambil $\mathrm{Ct}>1.0$ sehingga harga Tp akan membesar, sebaliknya jika Tp perhitungan lebih besar dari Tp pengamatan, harga diambil $\mathrm{Ct}<1.0$ agar harga Tp akan mengecil. Proses ini diulang agar $\mathrm{Tp}$ perhitungan mendekati $\mathrm{Tp}$ pengamatan. (Natakusumah,dkk,2011).

\section{a. Bentuk Dasar Hidrograph Satuan}

Menurut Natakususmah, dkk (2011) bentuk HSS dapat dinyatakan dengan berbagai persamaan-persamaan bentuk dasar HSS. Dua bentuk dasar HSS yang digunakan untuk HSS ITB-1 dan HSS ITB-2 sebagai berikut :

a) HSS ITB-1 memiliki persamaan lengkung naik dan lengkung turun seluruhnya yang dinyatakan dengan satu persamaan yang sama yaitu

$$
q(t)=\exp \left\{2-t-\frac{1}{t}\right\}^{\alpha c p}
$$

Pada persamaan diatas $\mathrm{t}=\mathrm{T} / \mathrm{Tp}$ dan $\mathrm{q}=\mathrm{Q} / \mathrm{Qp}$ masing-masing adalah waktu dan debit yang telah dinormalkan, dimana $\mathrm{t}=\mathrm{T} / \mathrm{Tp}$ berharga antara 0 dan 1 , sedang $\mathrm{q}=\mathrm{Q} / \mathrm{Qp}$. berharga antara 0 dan $\mathrm{Tb} / \mathrm{Tp}$. Harga koefisien $\alpha$ dan $\beta$ bergantung pada rumus time lag yang digunakan. Jika rumusan time lag menggunakan rumus Snyder dan Nakayasu,maka harga standar koefisien $\alpha$ dan $\beta$ untuk HSS ITB-1 dan HSS ITB-2 diberikan pada Tabel 1. Jika sangat diperlukan harga koefisien $\alpha$ dan $\beta$ dapat dirubah, namun untuk lebih memudahkan proses kalibrasi dilakukan dengan merubah koefisien $\mathrm{Cp}$.

Tabel 1 Harga Standar Koefisien $\alpha$ dan $\beta$

\begin{tabular}{|c|c|c|}
\hline \multirow{2}{*}{$\begin{array}{c}\text { Rumus time lag yang } \\
\text { digunakan }\end{array}$} & \multicolumn{2}{|c|}{ Harga Coeffisien Standar } \\
\cline { 2 - 3 } & $\begin{array}{c}\text { HSS } \\
\text { ITB-1 }\end{array}$ & HSS ITB-2 \\
\hline Snyder (Lc=1/2L) & $\alpha=1.50$ & $\alpha=2.50, \beta=1.00$ \\
\hline Nakayasu & $\alpha=0.62$ & $\alpha=2.50, \beta=0.72$ \\
\hline
\end{tabular}

Sumber : Natakusumah,dkk, 2011

Harga standar koefisien $\mathrm{Cp}$ adalah 1.0, jika harga debit puncak perhitungan lebih kecil dari debit puncak pengamatan, maka harga diambil $\mathrm{Cp}>1.0$ ini akan membuat harga debit puncak membesar, sebaliknya jika debit puncak perhitungan lebih besar dari hasil pengamatan maka harga diambil $\mathrm{Cp}<1.0$ agar harga debit puncak mengecil.

\section{c. Debit Puncak Hidrograph Satuan}

Dari definisi hidrograph satuan sintetis dan prinsip konservasi massa maka dapat disimpulkan bahwa volume hujan efektif satu satuan yang jatuh merata diseluruh DAS (VDAS) harus sama volume hidrograph satuan sintetis (VHS) dengan waktu puncak Tp. Jika bentuk dasar hidrograph satuan diketahui, dan harga waktu puncak dan waktu dasar diketahui, maka debit puncak hidrograph satuan sintetis akibat tinggi hujan satu satuan $\mathrm{R}=1 \mathrm{~mm}$ yang jatuh selama durasi hujan satu satuan $\operatorname{Tr}=1$ jam, adalah sbb :

$Q p=\frac{R}{3.6 T p} \frac{A_{D A S}}{A_{H S S}}$

Dengan rumusan diatas maka penerapan prinsip konservasi massa dalam perhitungan hidrograph banjir akan lebih mudah dijelaskan karena bentuknya lebih eksplisit (Natakusumah,dkk,2011).

\section{HSS Nakayasu}

Metode hidrograf satuan sintetik Nakayasu adalah metode paling sering dipakai di Indonesia, untuk menghitung hidrograf satuan DAS-DAS di Pulau Jawa. Metode Nakayasu mempunyai rumus pokok sebagai berikut:

dimana:

$\mathrm{Q}_{\mathrm{p}} \quad=$ debit puncak banjir $\left(\mathrm{m}^{3} / \mathrm{dt}\right)$

$\mathrm{C} \quad=$ Koefisien pengaliran DAS

$\mathrm{A} \quad=$ Luas DAS $\left(\mathrm{km}^{2}\right)$

$\mathrm{R} \quad=$ hujan satuan $(1 \mathrm{~mm})$

PUERSI PERANCANGAN PROGRAM HIDROGRAF SATUAN SINTESIS 9HSS) DENGAN METODE GAMA 1, NAKAYASU, DAN HSS ITB 1 
$\mathrm{T}_{\mathrm{p}} \quad=$ tenggang waktu dari permulaan hujan sampai dengan waktu puncak banjir (jam)

$\mathrm{T}_{0,3} \quad=$ tenggang waktu dari $\mathrm{T}$ sampai dengan waktu 30\% debit puncak (jam)

Waktu puncak $\left(\mathrm{T}_{\mathrm{p}}\right)$ dirumuskan sebagai berikut:

$T_{p}=T_{g}+0.058 t_{r}$

dimana:

$T g=0,21 L^{0,7}$

(L) $<15 \mathrm{~km}$

$T g=0,4+0,058 L \quad$ untuk panjang sungai

(L) $>15 \mathrm{~km}$

$\mathrm{Tr}=0,5 \mathrm{Tg}$ sampai $\mathrm{Tg}$

Adapun $\mathrm{T}_{0,3}$ dirumuskan sebagai berikut:

$T_{0,3}=\alpha T_{g}$

dimana:

$\alpha=1$ untuk DAS biasa

$\alpha=1.5$ untuk DAS dengan hidrograf naik yang cepat dan hidrograf turun yang lambat

$\alpha=3$ untuk DAS dengan hidrograf naik yang lambat dan hidrograf turun yang cepat

Debit pada hidrografnya dicari dengan rumus sebagai berikut:

a. Untuk bagian lengkung naik:

$$
Q_{a}=Q_{p}\left[\frac{t}{T_{p}}\right]^{2,4}
$$

dimana:

$\mathrm{Q}_{\mathrm{a}}=$ debit sebelum mencapai puncak

banjir

$\mathrm{T}=$ waktu dari permulaan hujan

sampai dengan waktu puncak banjir(jam)

b. Untuk bagian lengkung turun:

- Dari $\mathrm{T}_{\mathrm{p}}$ sampai dengan $\mathrm{T}_{0,3}$

$$
Q_{d 1}=Q_{p} \cdot 0,3^{\frac{t-T_{p}}{T_{0,3}}}
$$

- Dari $\mathrm{T}_{0,3}$ sampai dengan $\mathrm{T}_{0,09}$

$$
Q_{d 2}=Q_{p} \cdot 0,3^{\frac{t-T_{p}+0,5 T_{0,3}}{1,5 T_{0,3}}}
$$

- Waktu untuk $\mathrm{T}_{<0,09}$

$$
Q_{d 3}=Q_{p} \cdot 0,3^{\frac{t-T_{p}+1,5 T_{0,3}}{2 T_{0,3}}}
$$

dimana:

$\mathrm{Q}_{\mathrm{d} 1}=$ debit antara $\mathrm{T}_{\mathrm{p}}$ sampai dengan $\mathrm{T}_{0,3}$

$$
\begin{aligned}
\mathrm{T}_{0,3} & =\text { tenggang waktu antara } \mathrm{Q} \\
& \text { sampai dengan } \mathrm{Q}_{0,3} \text { (jam) } \\
\mathrm{Q}_{\mathrm{d} 2} & \begin{array}{l}
\mathrm{p} \text { debit antara } \mathrm{T}_{0,3} \text { sampai dengan } \\
\mathrm{T}_{0,09}
\end{array} \\
\mathrm{~T}_{0,09} & =\text { tenggang waktu antara } \mathrm{Q}_{0,3} \\
& \text { sampai dengan } \mathrm{Q}_{0,09} \text { (jam) }= \\
& 1,5 \cdot \mathrm{T}_{0,3}
\end{aligned}
$$

Apabila hidrograf satuan sintetik telah ditemukan maka hidrograf akibat hujan-hujan yang lain dapat dicari dengan mengalikan debit pada hidrograf satuan dengan curah hujan yang jatuh. Grafik HSS Nakayasu seperti pada Gambar 3.

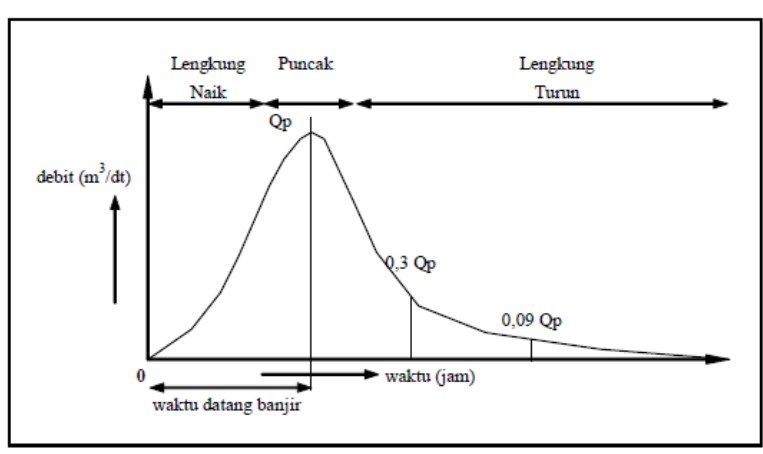

Gambar 3. HSS Nakayasu

\section{Metodologi}

Tahapan dalam perancangan program dengan menggunakan visual basic yaitu sebagai berikut (Gambar 4).

a. Perancangan lay out program

b. Pembuatan algoritma program

c. Instalasi program visual basic 6.0

d. Pembuatan program dengan membuat form-form sesuai dengan layout program.

e. Untuk verifikasi dari program yang dibuat, dilakukan dengan membandingkan hasil analisis program terhadap hasil analisis hitungan secara manual.

f. Setelah dilakukan verifikasi, kemudian program dapat di compile dan dijadikan program aplikasi yang siap untuk di install.

\section{Perancangan Program}

Program aplikasi Hidragraf Satuan Sintetik (HSS) ini dirancang dengan sederhana, sehingga pengguna bisa menggunakan program dengan mudah dan efektif. Program dirancang dengan memanfaatkan fasilitas yang terdapat 
dalam bahasa program visual basic (VB). Aplikasi Visual Basic dibentuk dari Form, Module, dan Class. Sebuah

form terdiri atas Properti, Prosedur, Event, dan Kontrol.

Langkah-langkah pembuatan aplikasi dengan visual basic yaitu:

1. Membuat antar-muka visual dengan objekobjek siap pakai buatan Microsoft atau pihak lain.

2. Mengubah nilai properti objek agar sesuai dengan aplikasi yang dibuat.

3. Menuliskan kode-kode untuk menghubungkan objek maupun kode program berdasarkan kombinasi dari perintah VB yang tersedia.

4. Menyimpan file proses pembuatan aplikasi (project) dalam direktori tersendiri.

Program aplikasi yang dirancang terdiri dari sembilan form antara lain:

1. Splash Form

2. Form $\log$ In
3. Form Menu Utama

4. Form HSS Gama1

\section{Form HSS ITB 1}

6. Form HSS Nakayasu

7. Form Input Data Umum Sungai

8. Form Input Data Hujan Efektif

9. Form Output

Form-form tersebut dirancang berdasarkan pengelompokan data dan analisis. Data yang digunakan sebagai input pada program aplikasi ini dibagi dua yaitu data umum dan data khusus. Data umum adalah data yang dapat diakses oleh semua pilihan metode analisis, sehingga dalam pembuatan program maupun dalam penggunaannya menjadi lebih praktis. Data umum tersebut dimasukkan dalam form input data umum sungai, terdiri dari datadata berikut: Nama sungai, Nama DAS, Luas DAS, Panjang Sungai Utama, Peta DAS

Data khusus adalah data yang hanya digunakan sebagai input pada salah satu metode analisis. Data khusus yang diperlukan untuk masingmasing metode seperti pada Tabel 2 .

Tabel 2. Input Data Untuk Masing-Masing Metode HSS

\begin{tabular}{|l|l|l|l|}
\hline No. & \multicolumn{1}{|c|}{ HSS Gama 1 } & \multicolumn{1}{c|}{ HSS ITB 1 } & \multicolumn{1}{c|}{ HSS Nakayasu } \\
\hline $\mathbf{1 .}$ & Jumlah Panjang Sungai Tingkat 1 & Nama DAS/Sungai & Nama DAS/Sungai \\
\hline $\mathbf{2 .}$ & $\begin{array}{l}\text { Jumlah Panjang Sungai Semua } \\
\text { Tingkat }\end{array}$ & $\begin{array}{l}\text { Luas daerah aliran Sungai } \\
\text { (A) }\end{array}$ & $\begin{array}{l}\text { Luas daerah aliran Sungai } \\
\text { (A) }\end{array}$ \\
\hline 3. & Jumlah Pangsa Sungai Tingkat 1 & Panjang Sungai Utama (L) & Panjang Sungai Utama (L) \\
\hline $\mathbf{4 .}$ & $\begin{array}{l}\text { Jumlah Pangsa Sungai Semua } \\
\text { Tingkat }\end{array}$ & Tinggi Hujan & Tinggi Hujan \\
\hline $\mathbf{5 .}$ & Lebar Atas DAS & Durasi Hujan & Durasi Hujan \\
\hline $\mathbf{6 .}$ & Lebar Bawah DAS & Koefisien waktu & $\begin{array}{l}\text { Koefisien pengaliran DAS ( } \\
\text { C ) }\end{array}$ \\
\hline $\mathbf{7 .}$ & Elevasi Hulu Sungai & Koefisien puncak & \\
\hline $\mathbf{8 .}$ & Elevasi Hilir Sungai & Alpha & \\
\hline $\mathbf{9 .}$ & Luas DAS & & \\
\hline $\mathbf{1 0 .}$ & Panjang Sungai Utama & & \\
\hline
\end{tabular}


11. Tinggi Hujan

12. Durasi Hujan 


\subsection{Algoritma}

Hal yang paling utama dalam menyelesaikan pekerjaan dengan bantuan komputer adalah bagaimana menentukan metoda penyelesaian atau prosedur yang jelas. Apabila metodanya telah ditetapkan usaha selanjutnya adalah pekerjaan rutin, yaitu menuliskan pekerjaan tersebut ke dalam bahasa komputer. Suatu prosedur yang jelas untuk menyelesaikan suatu persoalan dengan menggunakan langkah-langkah tertentu dan jumlah terbatas dinamakan algoritma.

Tahapan penyelesaian dalam aplikasi program ini dibagi menjadi beberapa tahapan yaitu:

1. Tahapan persiapan

2. Tahapan pemilihan metode

3. Tahapan input data umum

4. Tahapan analisis metode yang dipilih

5. Tahapan menampilkan output program

\subsection{Tampilan Program}

Tampilan luar dari program aplikasi ini terdiri dari beberapa jendela form layout tempat dimana objek atau kontrol sebagai mesin pada program aplikasi ini ditempatkan.

1. Splash Form, merupakan tampilan awal yang akan muncul pada saat program dijalankan (Gambar 4)

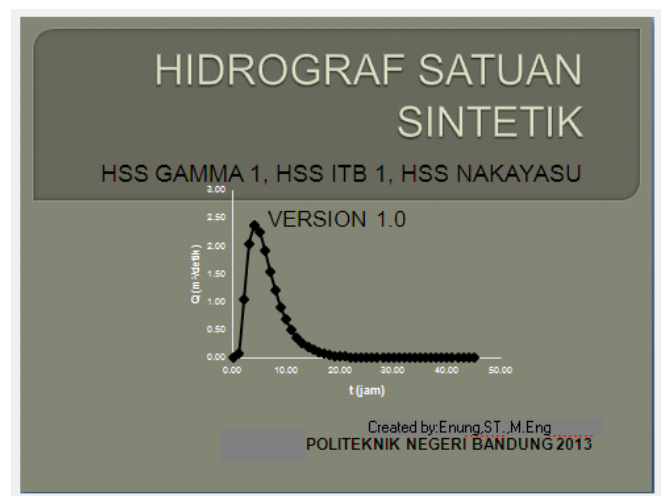

Gambar 4. Splash Form

2. Form Login, pada jendela form login pengguna (user) nantinya harus memasukan username dan password yang telah ditetapkan sebelumnya untuk dapat mengakses aplikasi program ini. Tampilan form Login seperti pada Gambar 5.

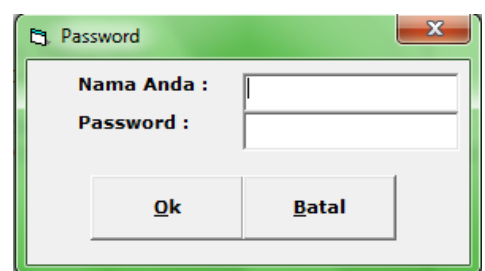

Gambar 5. Form Login

3. Form Menu, pada form ini terdapat pilihan program berdasarkan metode analisis HSS yang akan digunakan, dan database penyimpanan data. Pilihan metode HSS yang tersedia yaitu: HSS GAMA 1, HSS ITB 1, dan HSS Nakayasu. Tampilan Form Menu seperti pada Gambar 6.

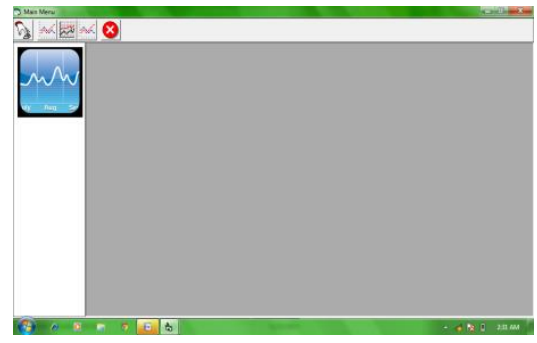

Gambar 6. Form Main Menu

4. Form Data Sungai, pada form ini berisi input data umum DAS dan peta DAS. Tampilan form data seperti pada Gambar 7. Data umum ini berlaku untuk semua metode analisa HSS.

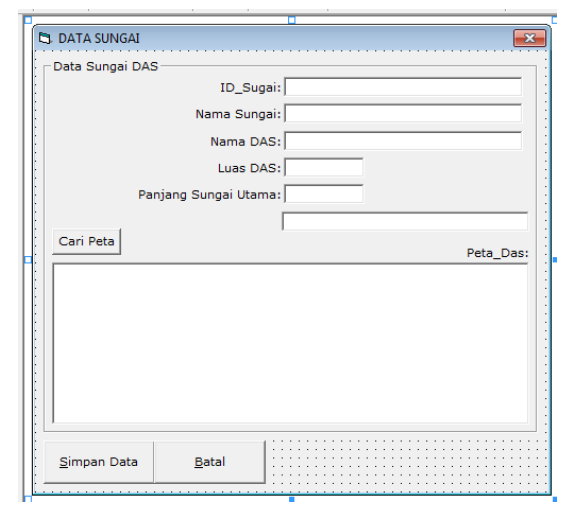

Gambar 7. Form Data Sungai

5. Form Daftar Sungai, form ini merupakan tempat penyimpanan data sungai yang telah dianalisis, sehingga pengguna program dapat memanggil kembali data yang sudah disimpan. Tampilan form daftar sungai seperti pada Gambar 8. 


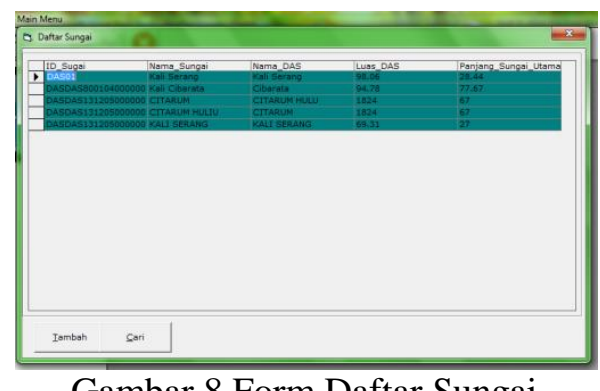

Gambar 8.Form Daftar Sungai

6. Form HSS Gama 1 merupakan jendela form layout yang terdiri dari input data parameter fisik DAS, analisa parameter DAS, analisa parameter HSS Gama 1 dan Tabel hasil HSS Gama 1. Tampilan form HSS Gama 1 seperti pada Gambar 9.

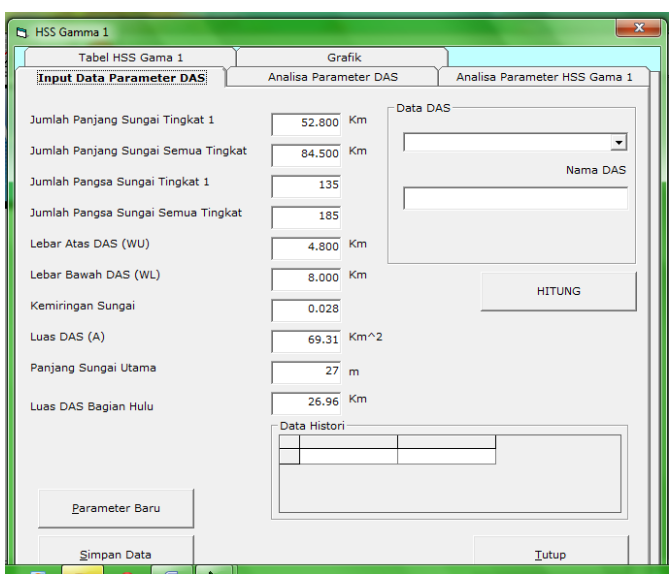

Gambar 9. Form HSS Gama 1

7. Form HSS ITB 1, merupakan jendela form layout yang terdiri dari input data parameter DAS, Perhitungan waktu puncak dan debit puncak dan Tabel HSS ITB. Tampilan form HSS ITB 1 seperti pada Gambar 10 sampai Gambar 12 .

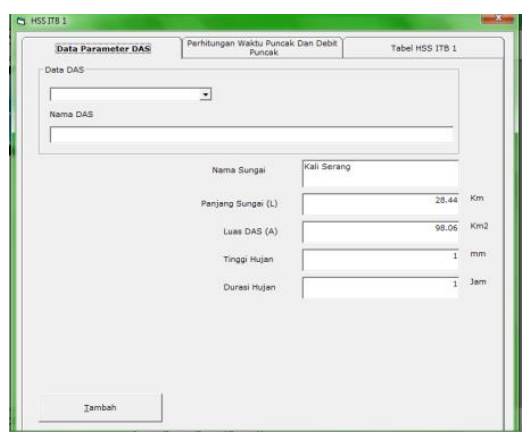

Gambar 10. Form HSS ITB 1 (Data Parameter DAS)

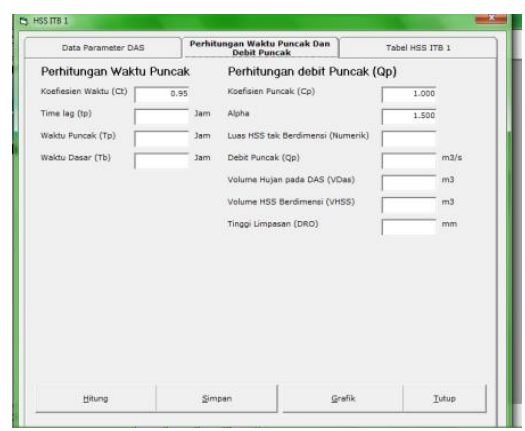

Gambar 11. Form HSS ITB 1 (Perhirtungan Waktu Puncak dan Debit Puncak)

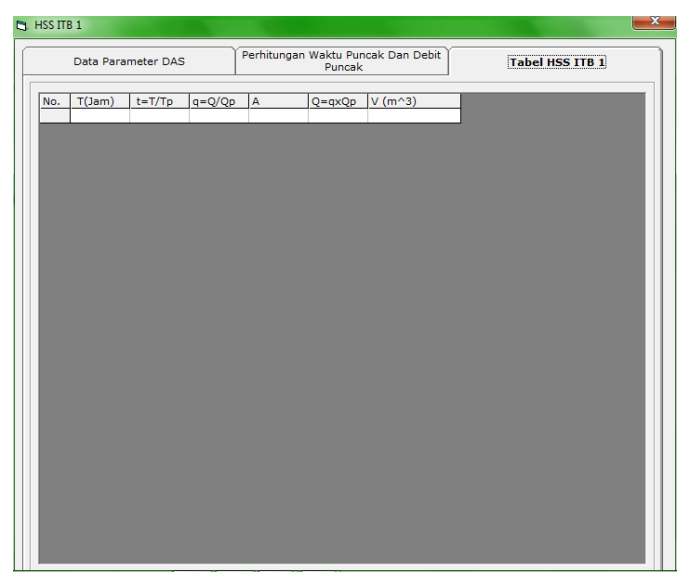

Gambar 12 Form HSS ITB 1 (Tabel HSS ITB 1)

8. Form HSS Nakayasu, merupakan jendela form layout yang terdiri dari input data parameter fisik DAS, analisa debit puncak, dan Tabel hasil HSS Nakayasu. Tampilan form HSS Gama 1 Nakayau seperti pada Gambar 13.

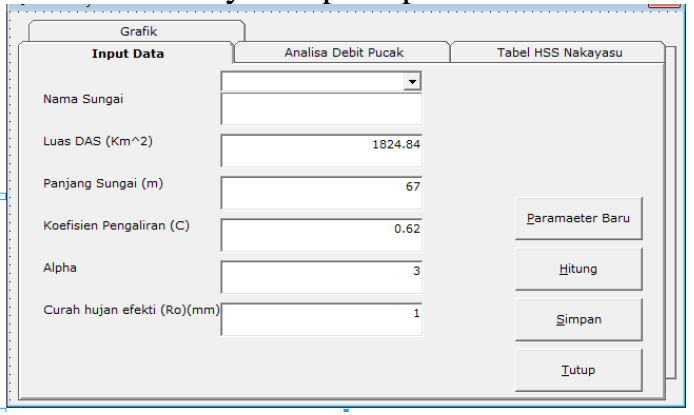

Gambar 13. Form HSS Nakayasu

\subsection{Contoh Penggunaan Program Aplikasi HSS}

Setelah tampilan program selesai dibuat, tahap berikutnya adalah menguji program aplikasi tersebut. Untuk menguji program aplikasi ini, digunakan data sekunder sebagai input data. Pemilihan Das sebagai contoh kasus berdasarkan ketersediaan data yang ada, jadi 
dalam hal ini Das yang dijadikan kasus berbedabeda untuk metode HSS Gama 1, HSS ITB 1, dan HSS Nakayasu.

\subsubsection{Metode HSS Gama 1}

Contoh penggunaan program aplikasi HSS untuk metode HSS Gama 1 dengan data DAS Sungai Cipedak. Input data parameter DAS dimasukkan pada Form HSS Gama 1 dan pada SSTABInput Data Parameter DAS. Tampilan Input Data Parameter DAS seperti pada Gambar 14.

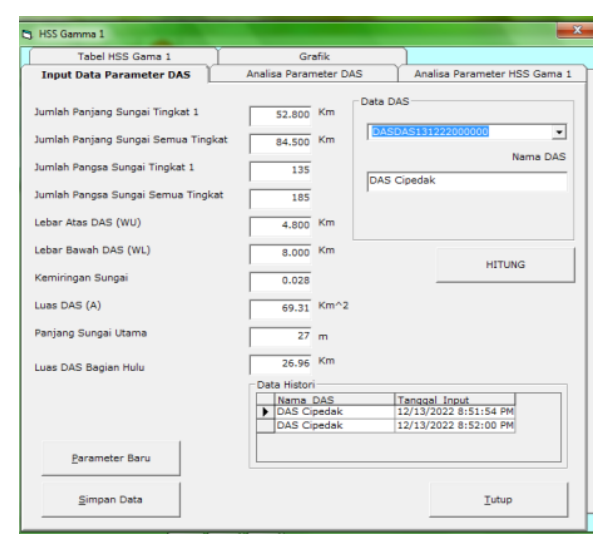

Gambar 14. Tampilan Input Data Parameter DAS

Apabila input data sudah dimasukkan dengan benar dan lengkap (tidak boleh ada data yang kosong) kemudian tekan tombol Hitung untuk analisis HSS Gama 1. Tampilan output dari hitungan HSS Gama 1 seperti pada Gambar 15 dan Gambar 16.

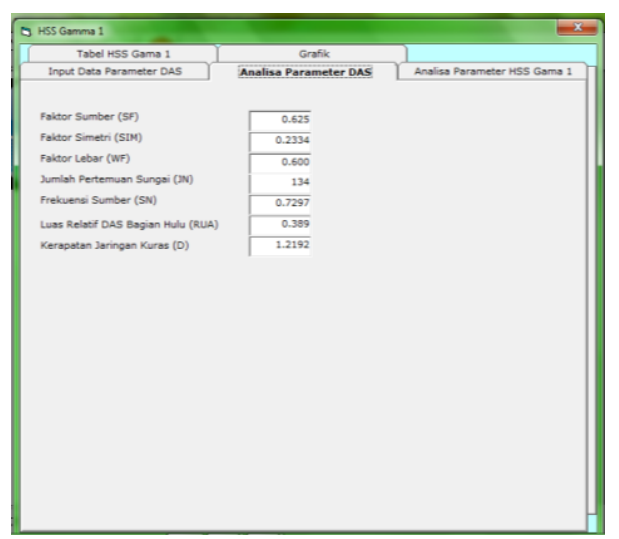

Gambar 15. Tampilan output Analisa Parameter DAS

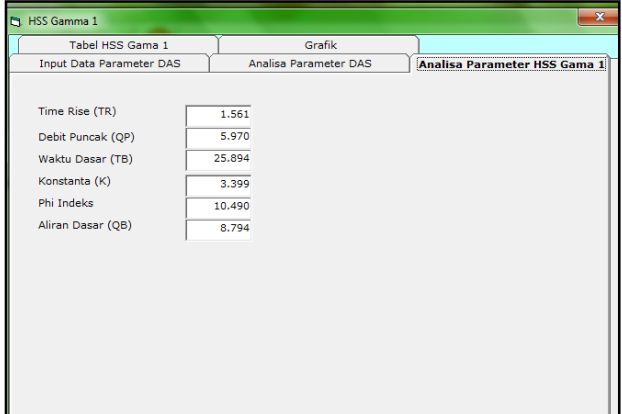

Gambar 16. Tampilan Output Analisa Parameter HSS Gama 1

Gambar 17. merupakan tampilan dari hasil analisa parameter DAS yang nantinya akan digunakan sebagai input data untuk menghitung analisa parameter HSS Gama 1 yang terdiri dari Time rise (Tr), Debit Puncak (Qp), Waktu Dasar (TB), Konstanta (K), Phi Indeks, dan Aliran Dasar (QB). Adapun tabel HSS Gama 1 seperti pada Gambar 17.

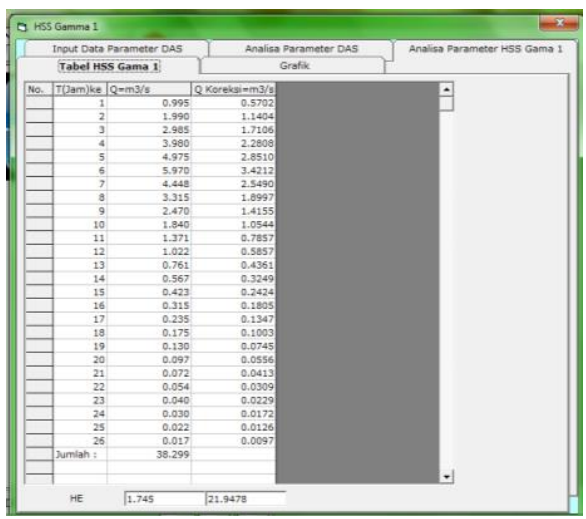

Gambar 17. Tampilan Form Tabel HSS Gama 1

Output akhir dari program aplikasi ini yaitu grafik hidrograf satuan seperti ditampilkan pada Gambar 18.

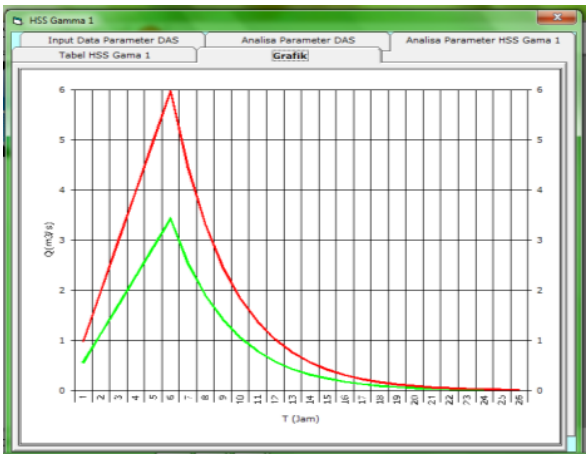

Gambar 18. Grafik Hidrograf Satuan HSS Gama 1

\subsubsection{Metode HSS ITB 1}

Contoh penggunaan program aplikasi HSS untuk metode HSS ITB 1 dengan data DAS 
CIBATARUA dengan data parameter DAS sebagai berikut:

1. Nama Sungai $=$ Cibatarua

2. Luas daerah aliran Sungai $(A)=56.92 \mathrm{Km}^{2}$

3. Panjang Sungai Utama $(\mathrm{L})=12.15 \mathrm{Km}$

4. Tinggi Hujan $=1.00 \mathrm{~mm}$

5. Durasi Hujan $\operatorname{Tr}=1.00 \mathrm{Jam}$

Data yang digunakan merupakan data sekunder yang diperoleh dari referensi jurnal yang berjudul Prosedur Umum Perhitungan Hidrograph Satuan Sintetis (Hss) Untuk Perhitungan Hidrograph Banjir Rencana. Studi Kasus Penerapan Hss ITB-1 Dan Hss ITB-2 Dalam Penentuan Debit Banjir Untuk Perencanaan Pelimpah Bendungan Besar Tahapan input data pada program aplikasi HSS ini yaitu dengan memasukkan data parameter DAS dan durasi hujan selama satu jam. Tampilan input data untuk metode HSS ITB 1 seperti pada Gambar 19.

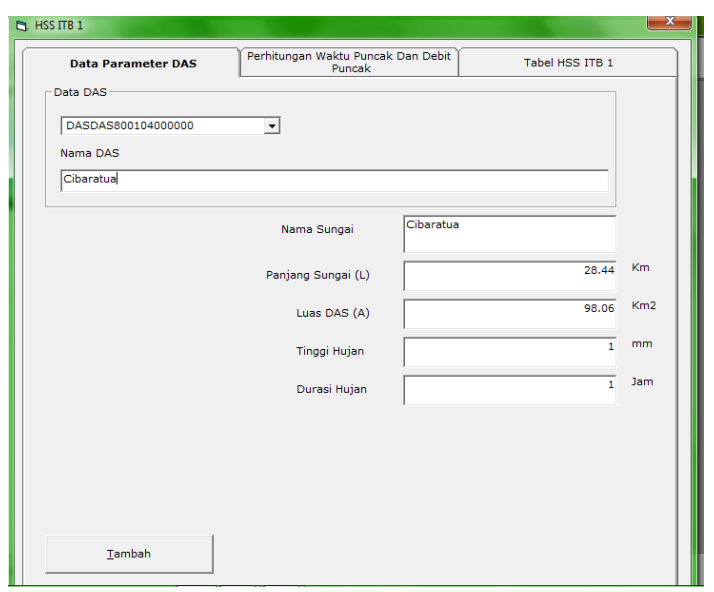

Gambar 19. Tampilan Input Data Parameter DAS HSS ITB 1

Hasil perhitungan waktu puncak (Tp), waktu dasar (Tb), dan debit puncak seperti ditampilkan pada Gambar 20.. Pada bagian perhitungan waktu puncak dan debit puncak ada input data yang harus dimasukkan yaitu Koefisien waktu $(\mathrm{Ct})$, koefisien debit (Cp), dan Alpha. Data tersebut melalui analisis terpisah dan tidak dibahas dalam program aplikasi ini.

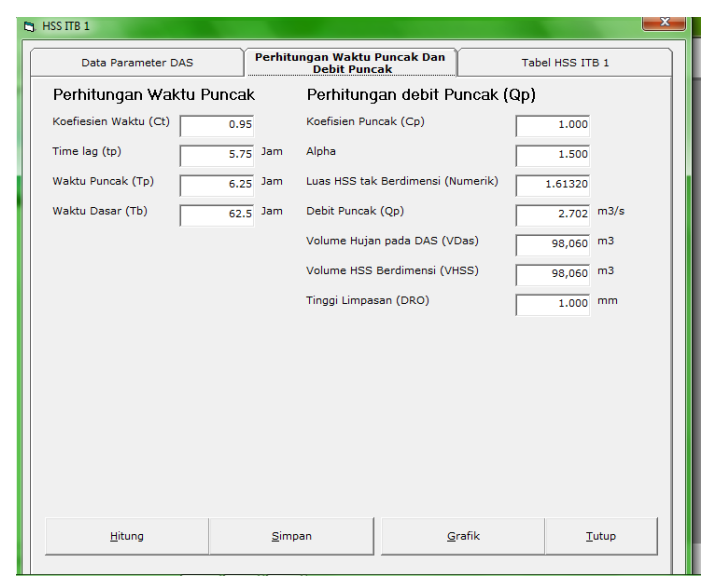

Gambar 20. Tampilan Perhitungan Waktu Puncak dan Debit Puncak

Tabel HSS ITB 1 yang merupakan output dari program ini untuk metode HSS ITB 1seperti terlihat pada Gambar 21. Sedangkan untuk grafik HSS ITB 1 hasil analisis menggunakan program aplikasi ini seperti pada Gambar 22.

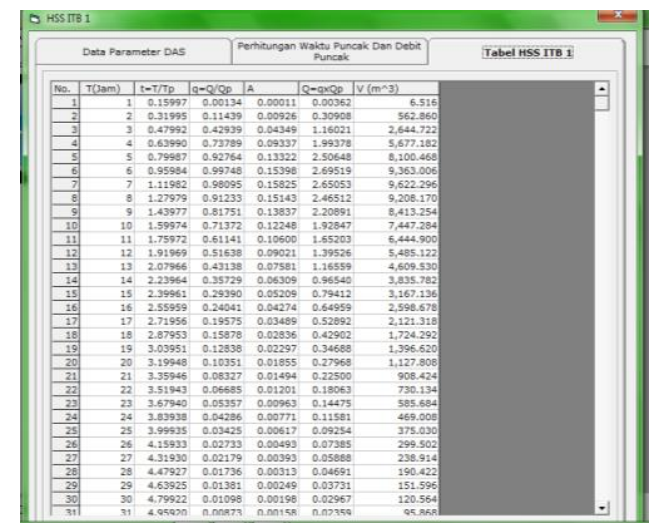

Gambar 21. Tampilan Output Tabel HSS ITB 1

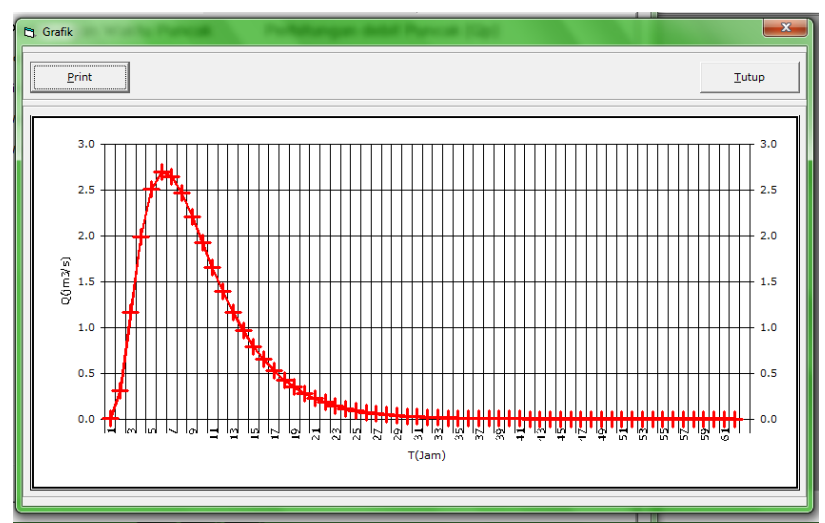

Gambar 22. Grafik HSS ITB 1

\subsubsection{Metode HSS Nakayasu}


Untuk menguji program aplikasi HSS dengan metode Nakayasu digunakan data sekunder hasil penelitian terdahulu untuk Das Citarum Hulu segmen sungai Sapan-Nanjung. Form untuk menginput data pada program aplikasi ini yaitu seperti pada Gambar 23. Input data yang diperlukan pada metode ini yaitu data luas DAS, panjang sungai, dan parameter hidrograf $(\alpha)$.

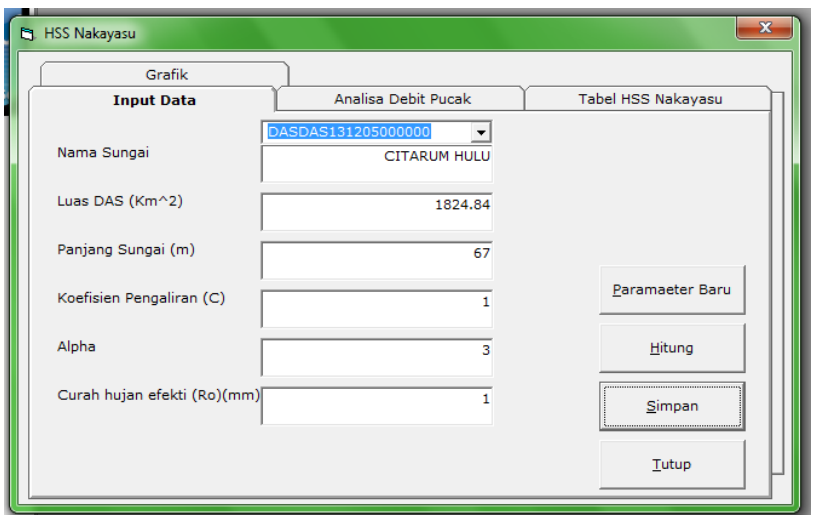

Gambar 23. Tampilan Input Data Metode HSS Nakayasu

Adapun hasil analisa debit puncak ditampilkan pada Tab Analisa Debit Puncak yang akan diproses setelah tombol Hitung ditekan. Tampilan hasil analisa debit puncak seperti ditampilkan pada Gambar 24.

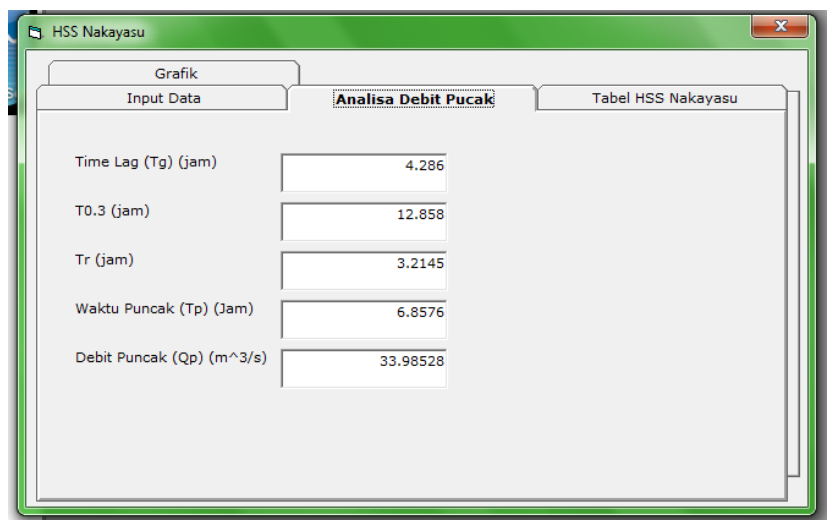

Gambar 24. Tampilan Hasil Analisa Debit Puncak

Dengan menggunakan persamaan Nakayasu, diperoleh tabel hidrograf satuan sintetik HSS Nakayasu seperti ditampilkan pada Gambar 25. Output yang ditampilkan pada table tersebut adalah nilai debit dan nilai debit koreksi. Sedangkan Grafik HSS Nakayasu seperti pada Gambar 26.

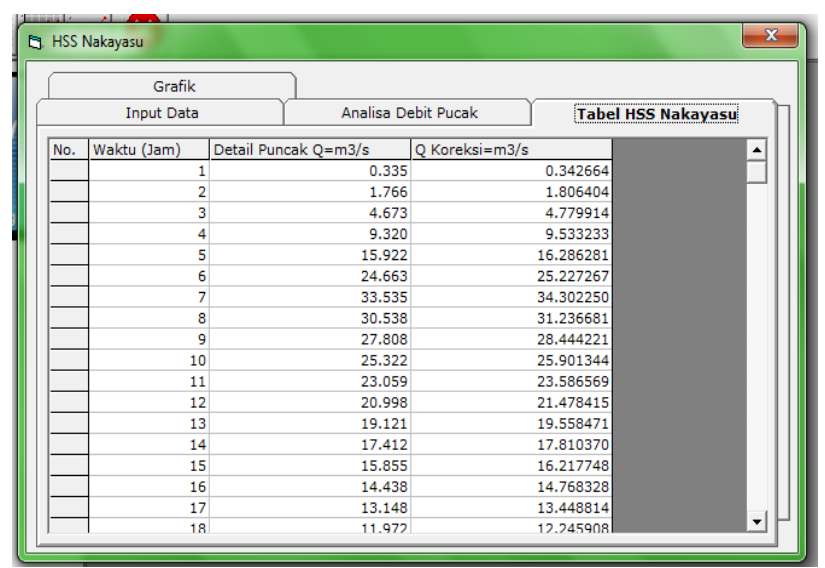

Gambar 25. Tampilan Output Tabel HSS Nakayasu

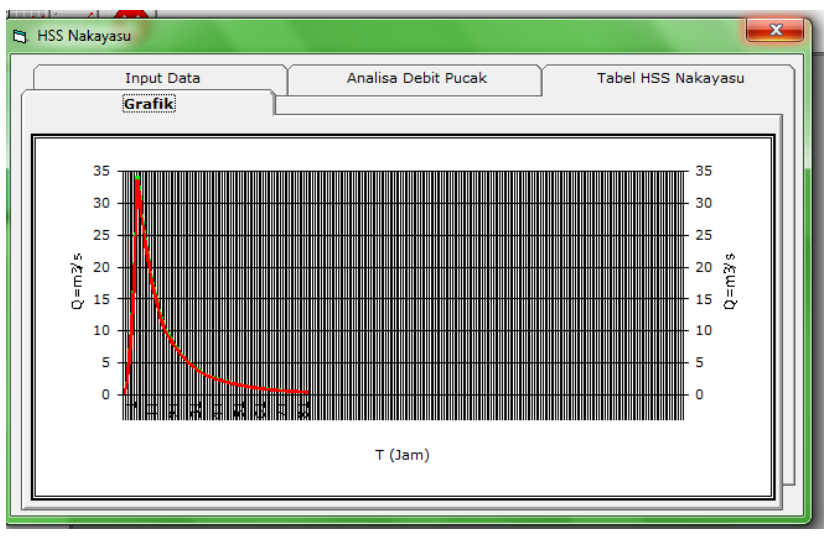

Gambar 26. Grafik HSS Nakayasu

\section{Kesimpulan}

Dari hasil penelitian dapat disimpulkan sebagai berikut:

1. Program aplikasi yang dibuat sudah dilakukan validasi dan diperoleh hasil yang sama dengan analisis menggunakan alat bantu hitung Ms.Excel.

2. Kelebihan dari program aplikasi ini adalah program aplikasi ini lebih praktis serta lebih mudah untuk dipahami, sehingga user yang akan menggunakan program aplikasi ini tidak perlu melakukan training khusus, tetapi dapat langsung menggunakan program dengan mengikuti panduan yang ada.

3. Kekurangan dari program aplikasi ini yaitu masih terbatas pada perhitungan hidrograf satuannya saja, sedangkan untuk menghitung hidrograf banjir harus menggunakan program lain atau perhitungan secara manual.

4. Program aplikasi ini merupakan alat bantu analisis, sehingga ketepatan hasil analisis tergantung kepada input data yang dimasukkan. 


\section{Daftar Pustaka}

Harto, S. Br, 1993, Analisis Hidrologi, PT. Gramedia Pustaka Utama, Jakarta.

Natakusumah, Dantje K,dkk, 2011, Prosedur Umum Perhitungan Hidrograf Satuan Sintetis dengan Cara ITB dan Beberapa Contoh Penerapannya, Jurnal Teknik Sipil Vol. 18 No. 3 Desember 2011, Bandung

Natakusumah, Dantje K,dkk, 2011, Prosedure Umum Perhitungan Hidrograph Satuan Sintetis (Hss) Untuk Perhitungan Hidrograph Banjir Rencana. Studi Kasus Penerapan Hss ITB-1 Dan Hss ITB-2 Dalam Penentuan Debit Banjir Untuk Perencanaan Pelimpah Bendungan Besar, Seminar Nasional Bendungan Besar 2011, Bandung

Sosrodarsono S dan Takeda K., 1987, Hidrologi Untuk Pengairan, Pradnya Paramita, Jakarta.

Triatmodjo, B., 2010, Hidrologi Terapan, Penerbit Beta Offset, Yogyakarta. 